\title{
Secreted singlestranded DNA is involved in the initial phase of biofilm formation by Neisseria gonorrhoeae
}

Zweig, Maria; Schork, Sabine; Koerdt, Andrea; Siewering, Katja; Sternberg, Claus; Thormann, Kai; Albers, SonjaVerena; Molin, Søren; Does, Chris, van der

\section{Published in:}

Environmental Microbiology

Link to article, DOI:

$10.1111 / 1462-2920.12291$

Publication date:

2014

Document Version

Publisher's PDF, also known as Version of record

Link back to DTU Orbit

Citation (APA):

Zweig, M., Schork, S., Koerdt, A., Siewering, K., Sternberg, C., Thormann, K., Albers, SV., Molin, S., \& Does, C. V. D. (2014). Secreted singlestranded DNA is involved in the initial phase of biofilm formation by Neisseria gonorrhoeae. Environmental Microbiology, 16(4), 1040-1052. https://doi.org/10.1111/1462-2920.12291

\section{General rights}

Copyright and moral rights for the publications made accessible in the public portal are retained by the authors and/or other copyright owners and it is a condition of accessing publications that users recognise and abide by the legal requirements associated with these rights.

- Users may download and print one copy of any publication from the public portal for the purpose of private study or research.

- You may not further distribute the material or use it for any profit-making activity or commercial gain

- You may freely distribute the URL identifying the publication in the public portal 


\section{Secreted single-stranded DNA is involved in the initial phase of biofilm formation by Neisseria gonorrhoeae}

\author{
Maria Zweig, ${ }^{1}$ Sabine Schork, ${ }^{1}$ Andrea Koerdt, ${ }^{2}$ \\ Katja Siewering, ${ }^{1}$ Claus Sternberg, ${ }^{3}$ Kai Thormann, ${ }^{1}$ \\ Sonja-Verena Albers, ${ }^{2}$ Søren Molin $^{3}$ and \\ Chris van der Does ${ }^{1 *}$ \\ ${ }^{1}$ Department of Ecophysiology and \\ ${ }^{2}$ Molecular Biology of Archaea Max-Planck-Institute for \\ terrestrial Microbiology, Marburg, Germany. \\ ${ }^{3}$ Department of Systems Biology, Technical University of \\ Denmark, Lyngby, Denmark.
}

\section{Summary}

Neisseria gonorrhoeae is an obligate human pathogen that colonizes the genital tract and causes gonorrhoea. Neisseria gonorrhoeae can form biofilms during natural cervical infections, on glass and in continuous flow-chamber systems. These biofilms contain large amounts of extracellular DNA, which plays an important role in biofilm formation. Many clinical isolates contain a gonococcal genetic island that encodes a type IV secretion system (T4SS). The T4SS of $\boldsymbol{N}$. gonorrhoeae strain MS11 secretes SSDNA directly into the medium. Biofilm formation, studied in continuous flow-chamber systems by confocal laser scanning microscopy (CLSM), was strongly reduced, especially in the initial phases of biofilm formation, in the presence of Exonuclease I, which specifically degrades ssDNA or in a $\triangle$ tra $B$ strain that does not secrete ssDNA. To specifically detect SsDNA in biofilms using CLSM, a novel method was developed in which thermostable fluorescently labelled ssDNAand ss/dsDNA-binding proteins were used to visualize ssDNA and total DNA in biofilms and planktonic cultures. Remarkably, mainly dsDNA was detected in biofilms of the ssDNA secreting strain. We conclude that the secreted ssDNA facilitates initial biofilm formation, but that the secreted ssDNA is not retained in mature biofilms.

Received 11 June, 2013; accepted 23 September, 2013. *For correspondence. E-mail does@mpi-marburg.mpg.de; Tel. (+49) 6421178 334; Fax (+49) 6421178209
Introduction

Biofilms are surface-attached microbial communities embedded in a self-produced extracellular matrix of polymeric substances (Costerton et al., 1999). About $80 \%$ of the world's microbial biomass resides in biofilms, and more than $75 \%$ of human microbial infections are assisted by the formation of stable biofilms (Davies, 2003). During biofilm, formation bacteria undergo a transition from a planktonic to an aggregated form that is embedded in an exopolymeric matrix. During this transition, planktonic bacteria first attach to the surface. This attachment is initially reversible and becomes irreversible once the bacteria start to produce extracellular polymeric substances like exopolysaccharides, secreted proteins, membrane vesicles and extracellular DNA (eDNA) (Dunne, 2002). The extracellular polymeric substance is essential for maturation of the biofilm and can constitute up to $90 \%$ of its biomass (Lemming et al., 2000). Extracellular polymeric substances produced by different bacteria is diverse in its composition, but for many organisms, like Pseudomonas aeruginosa (Whitchurch et al., 2002), Streptococcus pneumonia (Moscoso et al., 2006), Enterococcus faecalis (Thomas et al., 2008), Staphylococcus aureus (Rice et al., 2007), Staphylococcus epidermidis (Qin et al., 2007), Haemophilus influenza (Izano et al., 2009), Shewanella oneidensis (Godeke et al., 2011a), Neisseria meningitidis (Lappann et al., 2010) and Neisseria gonorrhoeae (Steichen et al., 2011), it was demonstrated that eDNA is an important component of the biofilm. A common mechanism by which eDNA is released into the biofilm is autolysis. Different mechanisms that induce autolysis have been identified. For example, in $P$. aeruginosa, a part of the population lyses under the control of a quorum sensing system (Allesen-Holm et al., 2006), while in E. faecalis autolysis occurs via a fratricidal mechanism (Thomas et al., 2009). In S. aureus, autolysis originates from a programmed cell death similar to apoptosis of eukaryotic cells (Yang et al., 2006). DNA can also be released via active secretion, as has been observed in P. aeruginosa (Hara and Ueda, 1981) and in N. gonorrhoeae (Hamilton et al., 2005). The release of vesicles-containing DNA (Kadurugamuwa and Beveridge, 1996) and prophage-mediated lysis of a subpopulation of cells (Webb et al., 2003; Godeke et al., 
2011a) are further possible sources of eDNA. The amount of DNA is further regulated by nucleases (Mann et al., 2009; Godeke et al., 2011b; Steichen et al., 2011).

Thus, DNA is known as one of the major structural components of many bacterial biofilms (Mulcahy et al., 2008; Flemming and Wingender, 2010; Fuxman Bass et al., 2010). The presence of DNA was demonstrated using different fluorescent probes that bound to DNA. None of the fluorescent probes used in these studies like, e.g., propidium iodide, 7-hydroxy-9H-(1,3-dichloro9,9-dimethylacridin-2-one (DDAO) (Allesen-Holm et al., 2006), SYTOX Orange (Harmsen et al., 2010), ethidium bromide (Allesen-Holm et al., 2006) and PicoGreen (Steinberger and Holden, 2005) can discriminate between ssDNA and dsDNA. The importance of DNA was also demonstrated by assessing the effect of DNase I treatment. Treatment with DNAse I often results in significant inhibition of biofilm formation and release of biomass from the formed biofilms (Whitchurch et al., 2002; Harmsen et al., 2010; Lappann et al., 2010). However, also DNase I treatment degrades both ssDNA and dsDNA. Thus, it is currently unknown whether different forms of DNA, such as e.g. ssDNA or dsDNA play specific and/or different roles in biofilm. The amounts of the different forms of DNA have also not been assessed before.

$N$. gonorrhoeae is an obligate human pathogen that primarily infects superficial mucosal surfaces lined with columnar epithelium such as urethra, cervix, rectum, pharynx and conjunctiva (Edwards and Apicella, 2004). As a sexually transmitted disease agent, the gonococcus normally colonizes the genital tract (Seifert, 1992). Most of the gonococcal infections in males are inflammatory and pyogenic infections of the urogenital tract, whereas about $50 \%$ of the infections in woman are asymptomatic (Pariser, 1972). Microscopic examination of human cervical tissue demonstrated that gonococci are capable to form biofilms during natural cervical infection (Steichen et al., 2008). Further studies revealed that $N$. gonorrhoeae can form biofilms both over glass, and over primary urethral and cervical epithelial cells and in continuous flow-chamber systems (Greiner et al., 2005). The structure of N. gonorrhoeae biofilms structurally resembled that of biofilms of other studied bacterial species (Greiner et al., 2005), although N. gonorrhoeae lacks genes capable of producing exopolysaccharides (Ferretti et al., 1997). Remarkably, networks of bacterial membranes, most likely derived from blebbing of the gonococcal outer membrane, were observed within the gonococcal biofilms (Greiner et al., 2005; Steichen et al., 2008).

As observed for many well-studied bacterial biofilms, the $N$. gonorrhoeae biofilms contain large amounts of DNA (Steichen et al., 2011). The possible sources of eDNA in gonococcal biofilms are diverse. Gonococci are well known to be highly autolytic (Elmros et al., 1976; Chan et al., 2012). For N. meningitidis, it was demonstrated that the release of DNA in biofilms was mediated by lytic transglycosylases, cytoplasmic $\mathrm{N}$-acetylmuramylL-alanine amidases and, at later stages of biofilm formation, by outer membrane phospholipase A (Lappann et al., 2010). Furthermore, the release of membrane blebs, which are associated with large amounts of DNA (Dorward et al., 1989), is also important for gonococcal biofilm formation (Steichen et al., 2008). Biofilm formation and remodelling is also influenced by the nuc nuclease, which has homology with the staphylococcus-secreted thermonuclease (Steichen et al., 2011). Another source of DNA within the biofilm might be the DNA secreted by the unusual type IV secretion system (T4SS) within a horizontally acquired region, the gonococcal genetic island (GGI) (Dillard and Seifert, 2001). The $57 \mathrm{~kb}$ large GGI is horizontally acquired and inserted in the dif site at the replication terminus (Hamilton et al., 2001; 2005). It is found in approximately $80 \%$ of the N. gonorrhoeae strains and encodes a T4SS (Dillard and Seifert, 2001). The T4SS of N. gonorrhoeae strain MS11 secretes single-stranded chromosomal DNA into the extracellular milieu in a contact-independent manner (Hamilton et al., 2005). The DNA secreted through the T4SS is taken up via the natural transformation system and contributes to the spread of genetic information (Ramsey et al., 2011).

The different physiochemical properties of ssDNA might have a different effect on biofilm formation than dsDNA. Here, the effect of ssDNA secreted by the T4SS on biofilm formation was studied in continuous flow-chamber systems by confocal laser scanning microscopy (CLSM). Furthermore, to specifically detect ssDNA in these biofilms, a novel method was developed in which thermostable fluorescently labelled ssDNA and ss/dsDNA binding proteins were used to visualize ssDNA and total DNA. It is demonstrated that the secreted ssDNA plays an important role in the initial phases of biofilm formation but the ssDNA is not retained in mature biofilms.

\section{Results}

\section{Exonuclease I inhibits the initial stages of biofilm formation}

To study whether the secreted ssDNA plays a role in biofilm formation, biofilm formation by $N$. gonorrhoeae strain MS11 was investigated in a continuous flow chamber system in the presence and absence of Exonuclease I, an enzyme which specifically degrades ssDNA. Purified Exonuclease I was highly specific for ssDNA in the medium used for the continuous flow experiments (see Fig. S1). Purified Exonuclease III, which normally is specific for dsDNA, degraded dsDNA efficiently, but in the medium used for the continuous flow experi- 
A
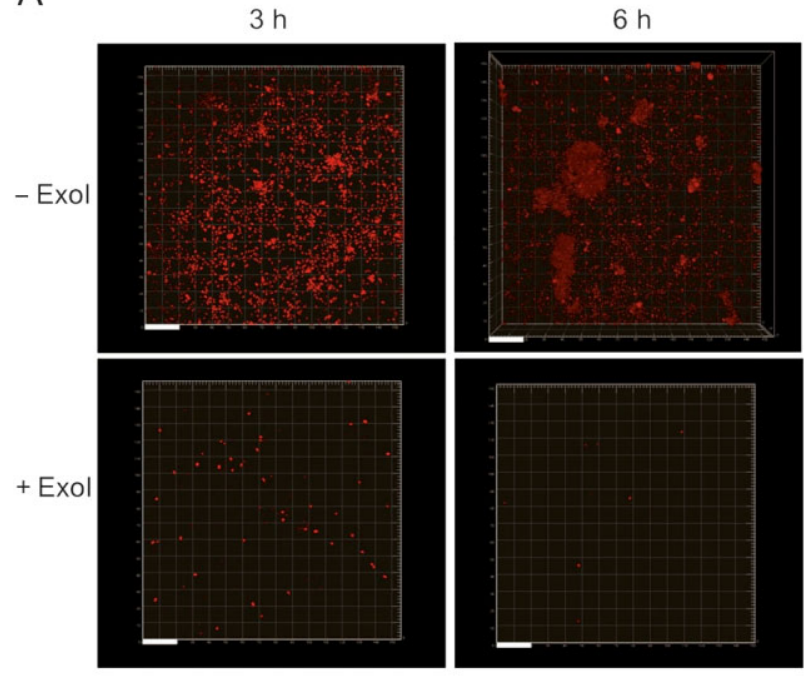

B

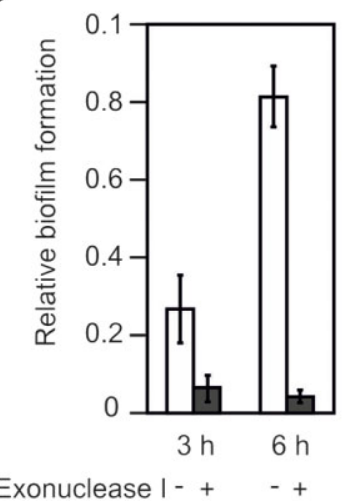

Fig. 1. The effect of Exonuclease I on initial attachment. Confocal microscopy of continuous flow chambers inoculated with

$N$. gonorrhoeae strain MS11 imaged 3 and $6 \mathrm{~h}$ after inoculation. The flow chambers contained minimal medium with or without Exonuclease I. The enzyme was refreshed every $2 \mathrm{~h}$.

A. The biofilm was stained with SYTO62 (red) and visualized by CLSM. Micrographs represent three-dimensional images. The bar is $20 \mu \mathrm{m}$ in length.

B. Quantification of the amount of biofilm in the images shown in (A). Images were processed and the biofilm mass was determined as the total number of voxels with IMARIS Software. Voxel numbers from five distinct channels were determined and averaged. The standard deviations between the channels are depicted as error bars. Biofilm formation is depicted relative to the amount of biofilm formed by MS11 after $24 \mathrm{~h}$ in the absence of Exol.

ments also showed significant activity against SsDNA (data not shown), and therefore could not be used to specifically degrade dsDNA. Biofilm development was monitored by CLSM after addition of the cell-permeant fluorescent nucleic acid stain SYTO62 after 3 and $6 \mathrm{~h}$ (see Fig. 1A). The quantification of the relative biofilm formation is shown in Fig. 1B. Almost no attached cells could be detected when Exonuclease I was added. This demon- strates that the presence of Exonuclease I affects biofilm formation by $N$. gonorrhoeae.

\section{DNA secretion facilitates biofilm formation}

Because biofilm formation was influenced by the addition of Exonuclease I, and thus most likely by the presence of ssDNA, it was tested whether the ssDNA secreted via the T4SS encoded within the GGI facilitates biofilm formation. Therefore, biofilm formation of $N$. gonorrhoeae strain MS11 and a MS11 strain in which the traB gene was deleted (MS11 $\triangle$ traB) were compared. The traB gene encodes a component of the T4SS core complex spanning the inner and outer membrane, and deletion of this gene results in the abolishment of DNA secretion (Ramsey et al., 2011). The traB mutation does not affect the growth rate (data not shown). To demonstrate that any observed effects were caused by the deletion of the traB gene, a strain was created in which the $\operatorname{tra} B$ gene was restored (MS11 $\operatorname{traB}:$ :traB). Because biofilm formation is strongly affected by the presence and absence of type IV pili (O'Toole and Kolter, 1998) and the type IV pili of $N$. gonorrhoeae can undergo both phase and antigenic variation (Seifert et al., 1988), piliation of the three strains was compared by comparing colony morphology after growth on plates, by sequencing the pilE gene, and by determining the expression levels of PilE by Western blotting with a PilE antibody. No differences between the three mutants were observed (data not shown).

Biofilms of the three strains were grown for 3 days in a continuous flow chamber system. After 48 and $72 \mathrm{~h}$, most of the surface was covered by strain MS11, and the formation of distinct three-dimensional structures was observed (see Fig. 2A). The quantification of biofilm formation is shown in Fig. 2B. Biofilm formation after 48 and $72 \mathrm{~h}$ was strongly reduced in MS11 $\Delta$ traB. The MS11 $\Delta$ traB::traB complementation strain showed similar biofilm formation as observed for strain MS11 after 48 and $72 \mathrm{~h}$, with coverage of most of the surface and formation of distinct three-dimensional structures (Fig. 2). This demonstrated that the MS11 $\operatorname{traB}$ mutant is strongly reduced in biofilm formation. This suggests that either the presence of the T4SS or a substrate secreted by the T4SS facilitates biofilm formation and contributes to the stabilization of the biofilm.

\section{Treatment of biofilms with Exonuclease I only affects strains that secrete SSDNA}

To test whether the effects of the mutation in $\operatorname{traB}$ and the addition of Exonuclease I are both caused by the absence of SsDNA in the medium or on the surface of the cell, it was tested whether these two effects are dependent or independent. Twenty-four-hours-old biofilms of MS11 and 
A
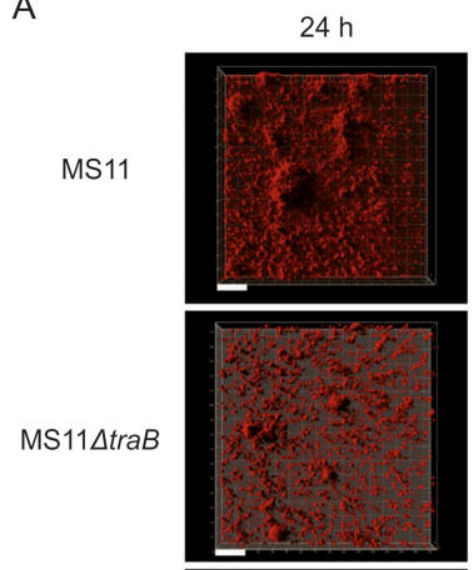

MS11 $\triangle \operatorname{traB}:: \operatorname{traB}$

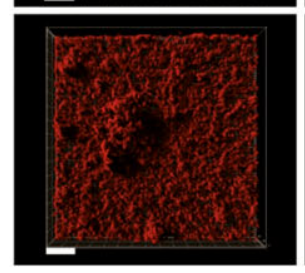

$48 \mathrm{~h}$
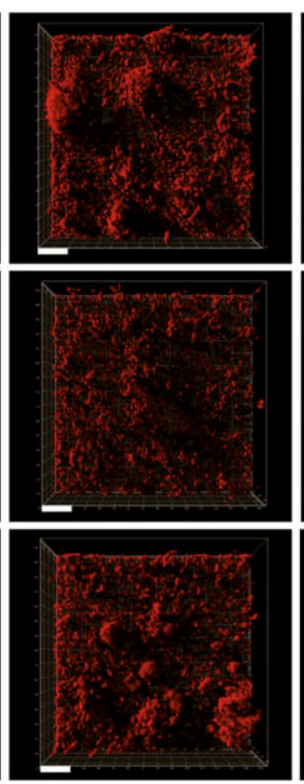

$72 \mathrm{~h}$
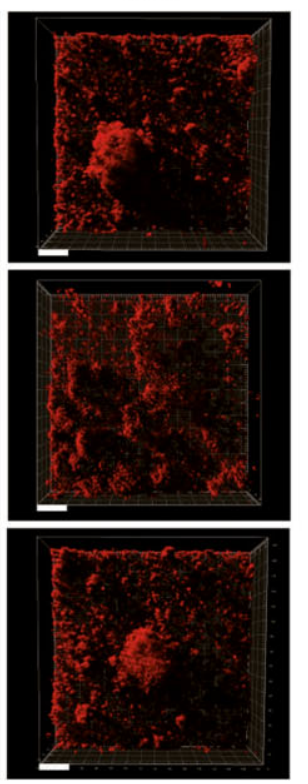

B

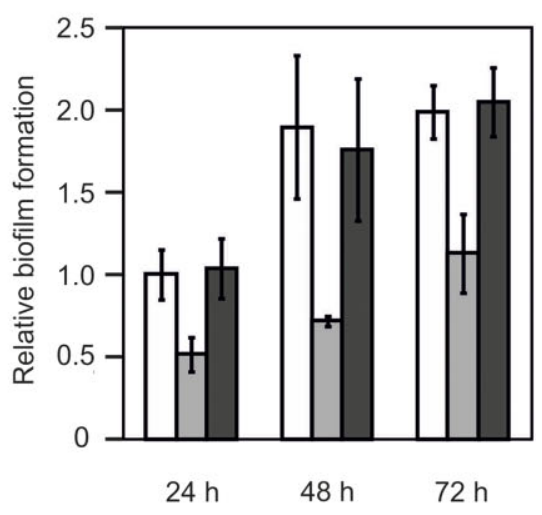

Fig. 2. Deletion of the traB gene results in a strong decrease of biofilm formation. Confocal microscopy of continuous flow chambers inoculated with N. gonorrhoeae strain MS11, MS11 $\Delta$ traB and MS11 1 traB::traB imaged 24, 48 and $72 \mathrm{~h}$ after inoculation.

A. The biofilm was stained with SYTO62 (red) and visualized by CLSM. Micrographs represent three-dimensional projections. The bar is $20 \mu \mathrm{m}$ in length.

B. Quantification of the amount of biofilm formed in (A). Images were processed as described in Fig. 1. The white, light grey and dark grey columns represent respectively the MS11, MS11 $\operatorname{traB}$ and MS11 $\mathrm{MtraB}:$ :traB strains. Biofilm formation is depicted relative to the amount of biofilm formed by MS11 after $24 \mathrm{~h}$.

the non-secreting mutant MS11 $\triangle$ traB were perfused for $1 \mathrm{~h}$ with medium with and without Exonuclease I (see Fig. $3 \mathrm{~A}$ and B). Because $24 \mathrm{~h}$ old biofilms of MS11 contain both single cells and/or microcolonies and mature threedimensional structures, the effects on both initial and later phase of biofilm formation can be studied at this timepoint. Again, biofilm formation was affected both in the MS11 $\Delta$ traB strain and by the addition of Exonuclease I. Treatment of $24 \mathrm{~h}$ old biofilms formed by strain MS11 resulted in the loss of part of the single cells and/or microcolonies, whereas no effects were observed on the distinct three-dimensional structures. Biofilm formation by the MS11 traB strain was not significantly affected by additional treatment with Exonuclease I. Thus, the effects of Exonuclease I treatment and the $\triangle t r a B$ mutation are not additive, demonstrating that the effects observed in the MS11 1 traB strain are caused by the absence of ssDNA. Remarkably, the effects of Exonuclease I were only observed for the single cells in the initial phases of biofilm formation but not for the distinct three-dimensional structures observed later in biofilm formation, suggesting that ssDNA plays a role in the initial phase of biofilm formation but not in mature biofilms. DNA has previously been proposed to function as a cell-to-surface and/or cell-to-cell adhesion during the initial phase of biofilm formation (Das et al., 2010). Based on the observations that biofilm for- mation by $N$. gonorrhoeae is affected by Exonuclease I treatment and by the $\triangle \operatorname{tra} B$ mutation, and that these effects are not additive, we propose that the ssDNA secreted via the T4SS plays an important role in biofilm development.

\section{Specific visualization of SsDNA in the presence of dsDNA}

Because our experiments provided evidence for a role of ssDNA in biofilm formation of $N$. gonorrhoeae strains, we set out to develop a technique to specifically visualize ssDNA. However, many different methods and stains are available to fluorescently detect DNA, such as ethidium bromide, propidium iodide, DDAO, SYTO60, SYBR Green, OliGreen and many others. To our knowledge, all currently available stains detect both SsDNA and dsDNA. In contrast, ssDNA-binding proteins (SSBs) bind to ssDNA with high specificity but without clear sequence specificity, and bind to dsDNA only with much lower affinity (Lohman and Ferrari, 1994). After initial attempts with purified SSBs from N. gonorrhoeae (SsbB) and Sulfolobus solfataricus (SSB), we set out to use TteSSB2 of Thermoanaerobacter tengcongensis to specifically detect ssDNA. This protein is highly stable and binds to ssDNA with high affinity $(\sim 150 \mathrm{nM}$ in the medium used for 
A

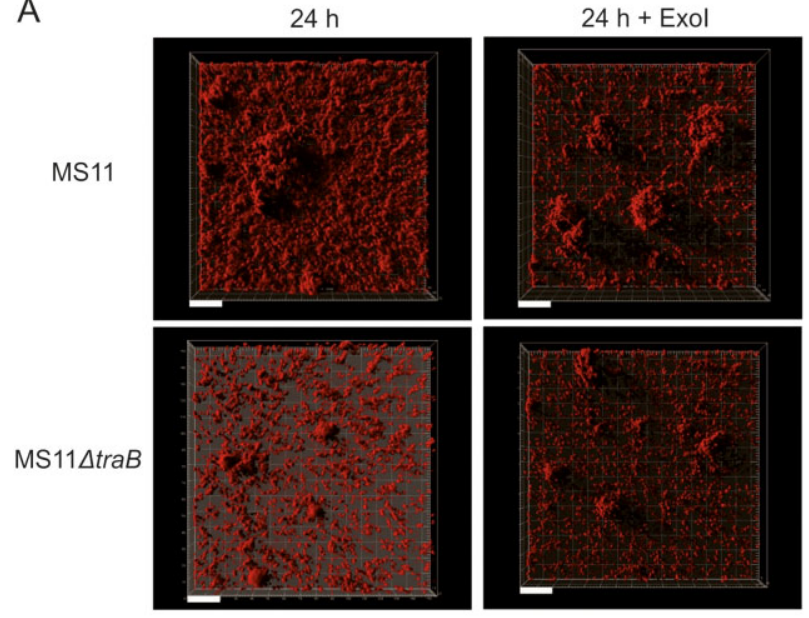

B

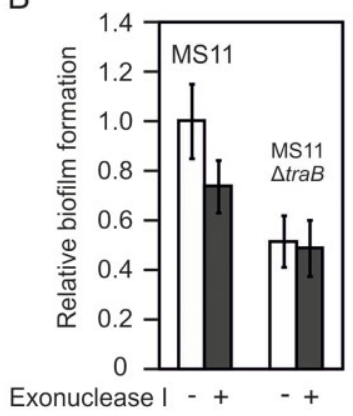

Fig. 3. The effect of Exonuclease I on $24 \mathrm{~h}$ old biofilms. Confocal microscopy of continuous flow chambers inoculated with $N$. gonorrhoeae strain MS11 and MS11 $\triangle$ traB. Continuous flow chambers were inoculated with the strains, and the system was perfused with medium for $24 \mathrm{~h}$. After $24 \mathrm{~h}$, the chambers were incubated for $1 \mathrm{~h}$ with medium with or without Exonuclease I. After this incubation, the chambers were perfused with medium and imaged.

A. Biofilm was stained with Syto62 (red) and visualized by CLSM. Micrographs represent three-dimensional images. The bar is $20 \mu \mathrm{m}$ in length.

B. Quantification of the amount of biofilm formed in (A). Images were processed as described in Fig. 1. Biofilm formation is depicted relative to the amount of biofilm formed by MS11 after $24 \mathrm{~h}$.

the continuous flow experiments, see Fig. S2C) in a sequence independent manner (Zhang et al., 2009). As a control for DNA binding, also the thermostable Sac7d protein from Sulfolobus acidocaldarius was overproduced and purified to homogeneity. Sac7d is a highly stable protein that was shown to bind dsDNA with high affinity in a sequence independent manner (Gao et al., 1998). However, in the medium used for the continuous flow experiments, Sac7d bound only slightly better to dsDNA $(\sim 4 \mu \mathrm{M}$, see Fig. S3C) than to ssDNA and therefore can only be used to image total DNA. Thus in culture medium, TteSSB2 binds sequence aspecific, but with high affinity to ssDNA specifically whereas Sac7d bound sequence aspecific to ssDNA and dsDNA. Because TteSSB binds to SsDNA with a 20-fold higher affinity than Sac7d to
ss/dsDNA, the sensitivity for the detection of SSDNA with TteSSB should be higher than the sensitivity for the detection of ss/dsDNA with Sac7d. TteSSB2 and Sac7d were fluorescently labelled on introduced cysteines. A detailed description of the purification, the DNA binding specificity, the optimization of fluorescent labelling for the different cysteine mutants and the characterization of the fluorescence properties of TteSSB2 and Sac7d is provided in the Supplementary Materials and Methods. Based on these experiments, TteSSB2 labelled at the cysteine introduced at the position of Trp55 (TteSSB2-W55C) and Sac7d labelled at the cysteine introduced at the position of Ser18 (Sac7d-S18C) were used to detect ss- and dsDNA respectively.

ssDNA and dsDNA can be visualized in biofilms of the thermoacidophilic crenarchaeon Sulfolobus acidocaldarius using fluorescently labelled TteSSB2 and Sac7d

To demonstrate that SsDNA and total DNA could indeed be visualized in biofilms using CLSM and fluorescently labelled TteSSB2 and Sac7d, the presence of SSDNA and dsDNA in biofilms of the crenarchaeon $S$. acidocaldarius was studied. It has previously been shown that 3 days old biofilms of $S$. acidocaldarius contain eDNA (Koerdt et al., 2010). This DNA is found at positions where cellular aggregates are visible and was sensitive to DNase I treatment. However, removal of the DNA had no effect on the structure of the biofilms, which suggested that eDNA does not play an important structural role in biofilms of S. acidocaldarius (Koerdt et al., 2010). Based on the conditions under which the S. acidocaldarius biofilms were grown $\left(76^{\circ} \mathrm{C}\right.$ and $\left.\mathrm{pH} 3.0\right)$, we assumed that the extracellular DNA was present as a mixture of denaturated ssDNA and dsDNA, and that therefore this system was well suited to test whether the fluorescently labelled TteSSB2 and Sac7d could be used to visualize DNA within the biofilm. In a first experiment, a 3 days old static biofilm of $S$. acidocaldarius was imaged by CLSM. The 3 days old biofilm was washed with Brock media of pH 5.0 and imaged by CLSM after incubation with DAPI (to visualize DNA inside and outside the cells), DDAO (to visualize the external DNA), IANBD-labelled TteSSB2-W55C (to visualize ssDNA) and Texas Red-labelled Sac7d-S18C (to visualize total DNA). As has been described previously, S. acidocaldarius readily formed biofilms, which contained a high density of cells and large aggregates, forming towering structures above the surface of attached cells. Labelling with DDAO showed the presence of external DNA which was associated with the large aggregates forming towering structures above the surface (Fig. 4A). The labelling with IANBD-labelled TteSSB2W55C showed a very similar labelling pattern as DDAO, 
A

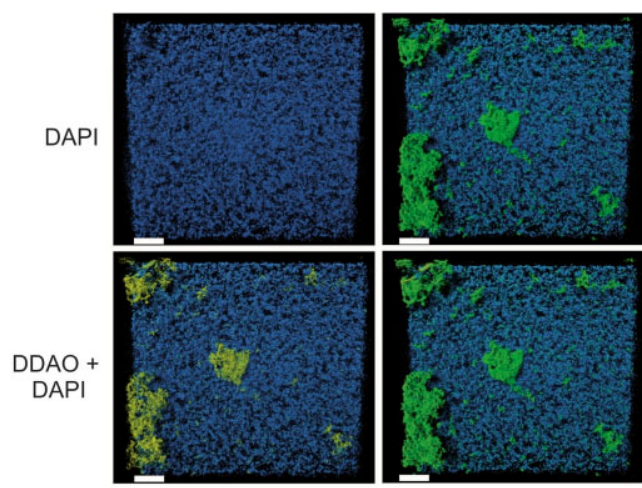

TteSSB2-IANBD + DAPI

TteSSB2-IANBD + DDAO + DAPI

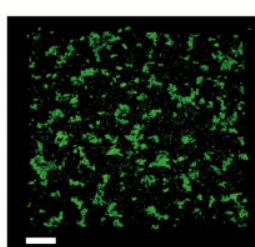

B
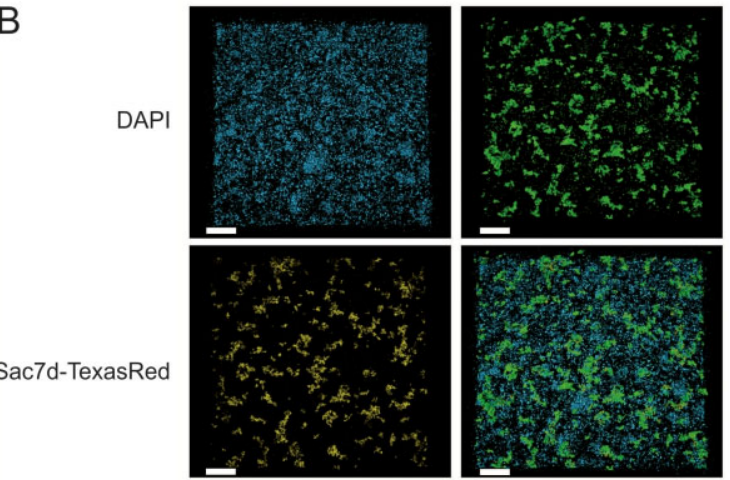

C

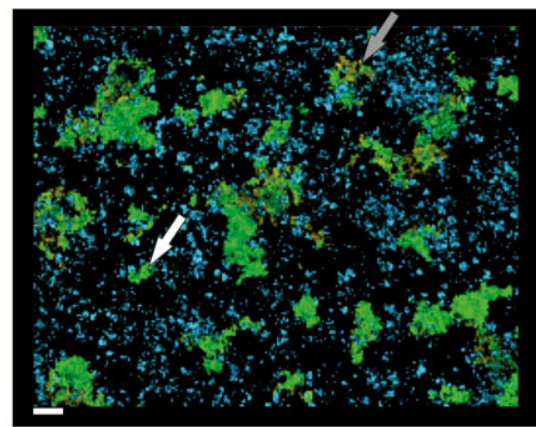

TteSSB2-IANBD

+ Sac7d-TexasRed
TteSSB2-IANBD + Sac7d-TexasRed
Fig. 4. Visualization of DNA in static biofilms formed by S. acidocaldarius. Three-day-old biofilms formed by $S$. acidocaldarius were labelled with (A) DAPI (blue), DDAO (yellow) and IANBD-labelled TteSSB2-W55C (green) or with (B) DAPI (blue), Texas Red-labelled Sac7d-S18C (yellow) and IANBD-labelled TteSSB2-W55C (green) and visualized by CLSM. The lower right panels show an overlay of the signals. (C) Enlargement of a part of the overlay shown in (B) is shown. Micrographs represent three-dimensional projections. The bar in (A) and (B) is $20 \mu \mathrm{m}$ in length, while the bar in (C) is $5 \mu \mathrm{m}$ in length. White and grey arrows depict positions where respectively ssDNA or dsDNA are labelled. demonstrating that IANBD-labelled TteSSB2-W55C was colocalizing with the DNA. Thus, large amounts of ssDNA can be detected in biofilms of $S$. acidocaldarius. In a second experiment, a 3 days old static biofilm of S. acidocaldarius was imaged after incubation with DAPI, Texas Red-labelled Sac7d-S18C and IANBD-labelled TteSSB2-W55C (Fig. 4B). Because the fluorescence spectra of DDAO and Texas Red overlap, these fluorophores could not be used at the same time. Both Texas Red-labelled Sac7d-S18C and IANBD-labelled TteSSB2-W55C specifically stained the large aggregates forming towering structures above the surface. Remarkably, although the labelling patterns of Sac7d-S18C and TteSSB2-W55C overlapped in many positions, several positions were only labelled with Sac7d-S18C or TteSSB2-W55C, demonstrating that the biofilm of $S$. acidocaldarius contained regions containing mainly ssDNA or dsDNA (Fig. 4C). Thus fluorescently labelled
TteSSB2 and Sac7d can be used to detect either SsDNA or total DNA in biofilms using CLSM.

Most extracellular DNA in biofilms of $\mathrm{N}$. gonorrhoeae MS11 is double-stranded

Because ssDNA might play an important role in the initial attachment of single cells to the surface, we tried to visualize ssDNA and total DNA in a $10 \mathrm{~h}$ old biofilm of MS11 (Fig. 5). At $10 \mathrm{~h}$ after inoculation, the formation of the distinct three-dimensional structures has started, but also single attached cells are still observed. Furthermore, in $10 \mathrm{~h}$ old biofilms, the single attached cells were still sensitive to Exonuclease I (data not shown). Thus under these conditions, we expect to be able to visualize ssDNA. To enable comparison of the amounts of ssDNA and total DNA, biofilms were incubated with IANBDlabelled Sac7d-S18C or IANBD-labelled TteSSB2-W55C 
A

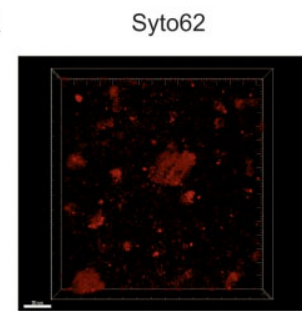

B

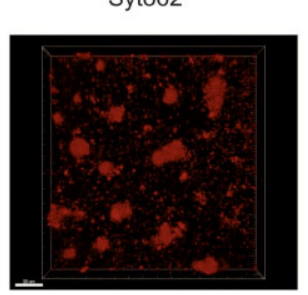

TteSSB2-IANBD

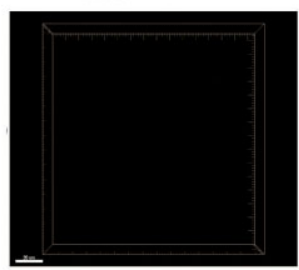

Sac7d-IANBD

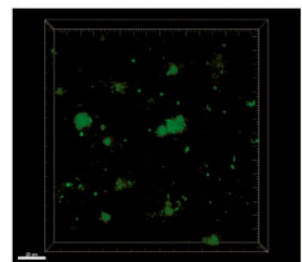

Syto62 + TtesSB2-IANBD

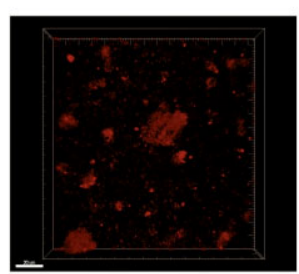

Syto62 +

Sac7d-IANBD

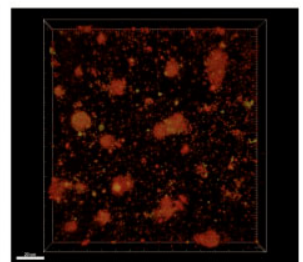

Fig. 5. Detection of ssDNA and dsDNA in $10 \mathrm{~h}$ old biofilms of $N$. gonorrhoeae. Confocal microscopy of continuous flow chambers inoculated with $N$. gonorrhoeae strain MS11 imaged $10 \mathrm{~h}$ after inoculation. The biofilm was stained with (A) Syto62 (red) and IANBD-labelled TteSSB2-W55C (green) or (B) Syto62 (red) and IANBD-labelled Sac7d-S18C (green) and visualized by CLSM. Micrographs represent three-dimensional projections. The bar is $20 \mu \mathrm{m}$ in length.
(Fig. 5). Both proteins showed approximately equal fluorescence intensities. Interestingly, a fluorescent signal was only found to colocalize with the distinct threedimensional structures after incubation with IANBDlabelled Sac7d-S18C but not after incubation with IANBD-labelled TteSSB2-W55C. Thus, only the protein that had affinity for dsDNA associated with the cells, whereas the protein with affinity for SsDNA remained in the medium (Fig. 5). Because we were not able to detect ssDNA associated with the biofilm under continuous flow conditions, we attempted to visualize ssDNA in planktonic cultures. IANBD-labelled Sac7d-S18C or IANBD-labelled TteSSB2-W55C was added to planktonic cultures followed by fluorescence microscopy (Fig. 6). After incubation with IANBD-labelled Sac7d-S18C, again a strong fluorescent signal was observed associated with the cells (Fig. 6A). After incubation with IANBD-labelled TteSSB2W55C, the fluorescent signal was found mainly in the medium, and not associated with cells (Fig. 6B). This shows that secreted SsDNA is not found associated with the cells, but is found in the medium, whereas dsDNA released from lysed cells remains mainly attached to the cells. Incubation of the cells with DNase I before incubation with IANBD-labelled Sac7d-S18C strongly reduced the labelling of the cells, demonstrating that the labelled DNA is accessible. To test whether externally added ssDNA would bind to the cells, cells were incubated with M13-derived ssDNA. At high concentrations of ssDNA, small amounts of IANBD-labelled TteSSB2-W55C were located at the cells, but most of IANBD-labelled TteSSB2W55C was still found in the medium (Fig. 6C). Thus, both in planktonic cultures and under continuous flow conditions, dsDNA is found mostly associated with cell surfaces, while the ssDNA is detected mainly in the medium. Because biofilm formation was strongly reduced in the presence of Exonuclease I and in a $\Delta$ traB strain that does
A

DIC

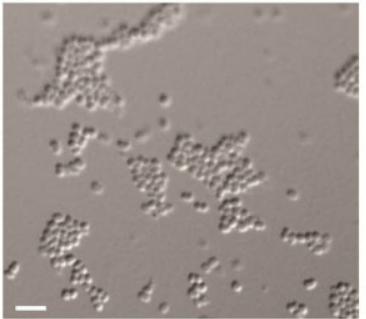

$\mathrm{B}$

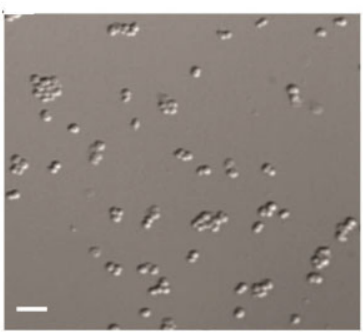

C

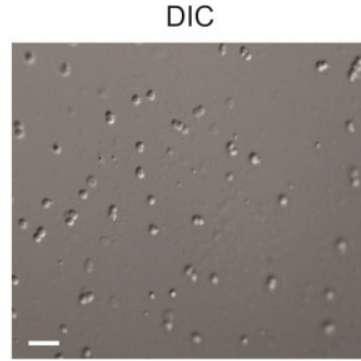

Sac7d-IANBD

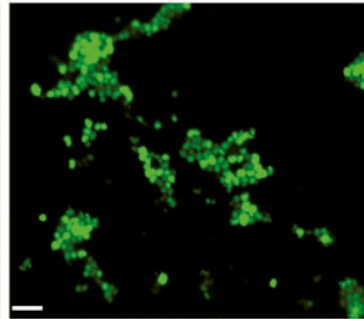

TteSSB2-IANBD

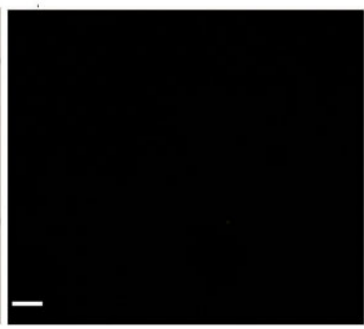

TteSSB2-IANBD + M13 ssDNA

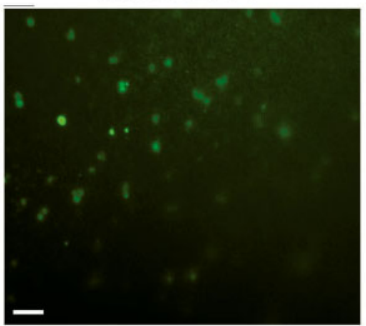

Fig. 6. Detection of ssDNA and dsDNA in an exponentially growing culture of $N$. gonorrhoeae. Neisseria gonorrhoeae MS11 was grown exponentially in minimal medium. The cells were incubated with $(A)$ IANBD-labelled Sac7d-S18C, (B) IANBD-labelled TteSSB2-W55C, or (C) incubated with IANBD-labelled TteSSB2-W55C after incubation with M13 ssDNA. The cells were visualized by DIC (left side) or CLSM (right side). Micrographs represent three-dimensional projections. The bar is $20 \mu \mathrm{m}$ in length. 
not secrete ssDNA, especially in the initial phases of biofilm formation we propose that initially, under conditions where still low amounts of dsDNA are available, the secreted ssDNA facilitates biofilm formation. At later stages, this function is performed by the dsDNA that remains better associated with bacterial cell surfaces.

\section{Discussion}

Extracellular DNA plays an important role in biofilm formation by N. gonorrhoeae (Steichen et al., 2011). Cultures of N. gonorrhoeae strain MS11 contain ssDNA, which is secreted directly into the medium via the T4SS encoded within the GGI (Salgado-Pabon et al., 2007). Biofilm formation of $N$. gonorrhoeae has previously not only been studied in MS11, a strain that contains the GGI, but also in N.gonorrhoeae strains 1291 and FA1090 which do not contain a GGI (Greiner et al., 2005). All three of these strains were able to form biofilms, demonstrating that the presence of the T4SS is not essential for biofilm formation. However, biofilm formation of $N$. gonorrhoeae is affected by many different factors, like the ability to release blebs (Steichen et al., 2008), the expression of Nuc, the extracellular thermonuclease (Steichen et al., 2011) and the presence of type IV pili. Many gonococcal genes, like the pilE gene, undergo rapid variation (Seifert et al., 1988), which complicates a direct comparison of different isolates. Because these other effects might mask an effect of the secreted ssDNA on biofilm formation, we have studied the effects of ssDNA secretion by comparing biofilm formation in MS11 with biofilm formation in a mutant and a complementation mutant directly derived from MS11, and show that actively secreted ssDNA facilitates biofilm formation of N. gonorrhoeae. Our data suggest that ssDNA plays an important role in the initial phases of biofilm formation and that this role is taken over by other components at later stages of biofilm formation. The $\triangle$ traB mutant that does not secrete ssDNA showed strongly reduced biofilm formation. The formation of the distinct three-dimensional structures observed in the wild type and complementation mutant was strongly reduced in the $\triangle \operatorname{tra} B$ mutant, and the stability of the formed biofilm was also strongly reduced. This is the first time that an effect of ssDNA on biofilm formation is demonstrated.

Lappann and colleagues (2010) demonstrated that in $N$. meningitidis, the capability to form biofilms differs between different lineages. In the most prevalent lineages, biofilm formation is dependent on DNA. These lineages form stable biofilms and show a very stable interaction with the host. Several less prevalent lineages do not use DNA for biofilm formation, and form much less stable biofilms. It was proposed that the lineages that do not use DNA for biofilm formation and show poor colonization properties compensate for their poor colonization properties by higher transmission rates. Possibly, in N. gonorrhoeae, the secretion of ssDNA via the T4SS modulates the colonization and transmission rates.

In this study, a method was developed to specifically detect ss- and dsDNA, using fluorescently labelled thermostable ssDNA- and dsDNA-binding proteins. Both proteins bind to DNA in an essentially sequence unspecific manner (Gao et al., 1998; Zhang et al., 2009). The fluorescent detection of the labelled proteins was optimized by introducing the fluorescent probes at positions where their fluorescence increases upon ssDNA binding. This reduces the signal of the proteins that are not bound to DNA. Detection of ssDNA using TteSSB2 of Thermoanaerobacter tengcongensis was highly specific, and ssDNA could be specifically detected in biofilms of $S$. acidocaldarius. TteSSB2 could also be used to detect ssDNA bound to N. gonorrhoeae strains, when ssDNA had been added to the culture. The Sac7d protein from $S$. acidocaldarius bound to dsDNA with higher affinity, but most likely will detect both ssDNA and dsDNA, especially since even secreted ssDNA will contain many positions where the ssDNA will anneal and form stretches of dsDNA. Localization of the DNA using fluorescently labelled Sac7d in N. gonorrhoeae biofilms showed that DNA was mainly localized inside the mature mushroomlike structures. This resembled the localization patterns of DNA found for N. gonorrhoeae using other DNA stains. Also, the localization of DNA using fluorescently labelled Sac7d in biofilms of S. acidocaldarius showed a pattern similar to what has been observed before using other DNA stains. This demonstrated that the use of these fluorescent proteins is a valid method to detect the DNA. Our approach could differentiate between ssDNA and total DNA. In biofilms of $S$. acidocaldarius, both ssDNA and dsDNA could be detected, while in the biofilms of N. gonorrhoeae, only dsDNA was detected. DNA has been found in different patterns for different organisms. For example, the extracellular DNA of $P$. aeruginosa is present in the microcolonies and organized as a grid-like structure on the substratum (Allesen-Holm et al., 2006), whereas the extracellular DNA in Bacillus cereus biofilms is evenly distributed over the surface, while in biofilms of Haemophilus influenzae and the gamma proteobacterium F8-5 eDNA occurs as filamentous strands (Bockelmann et al., 2006; Jurcisek and Bakaletz, 2007). Whether this DNA is single or double stranded is currently unknown, but can now be easily assessed with our newly developed method.

In this study, we attempted to detect both ss- and dsDNA within biofilms of $N$. gonorrhoeae. During the initial phases in which cells attach to the surface, and where 
experiments with Exonuclease I demonstrated that ssDNA plays an important role, neither ssDNA nor dsDNA could be detected. Most likely the amounts of ss- and dsDNA are too low for detection at these stages using the fluorescently labelled proteins. At later stages, the fluorescently labelled Sac7d protein detected DNA attached to the cells in the biofilms. Remarkably, at this stage, ssDNA, as detected by the fluorescent TteSSB2 protein, was found mainly in the medium. Thus, the ssDNA secreted via the T4SS plays a role in the initial stages of biofilm formation. At this stage, only very low amounts of DNA are present. At later stages, where large amounts of dsDNA are present, no ssDNA and no effects of SsDNA on biofilm formation could be detected.

\section{Experimental procedures}

\section{Materials}

Oligonucleotides and M13 ssDNA were purchased from Sigma-Aldrich (Steinheim, Germany). Restriction and, DNA-modifying enzymes were purchased from New England Biolabs (Frankfurt/Main, Germany). N-((2(iodoacetoxy)ethyl)- $N$-Methyl)amino-7-Nitrobenz-2-Oxa-1, 3-Diazole (IANBD-Ester), Fluorescein, Texas Red, 2-(4'maleimidylanilino)naphthalene-6-sulfonic acid (MIANS), 7hydroxy-9H-(1,3-dichloro-9,9-dimethylacridin-2-one) (DDAO) and Syto62 were purchased from Invitrogen (Darmstadt, Germany).

\section{Strains and growth conditions}

Neisseria gonorrhoeae strain MS11 and derivatives thereof (MS11 1 traB, MS11 traB::traB) used in this study are described in Table S1. Neisseria gonorrhoeae strains were plated from glycerol stocks on GC agar (BD Difco, Heidelberg, Germany) containing Kellogg's supplements (Kellogg et al., 1963) and grown overnight under $5 \% \mathrm{CO}_{2}$ at $37^{\circ} \mathrm{C}$. When necessary, chloramphenicol and/or erythromycin were added at the final concentration of $10 \mu \mathrm{g} \mathrm{ml}^{-1}$.

Escherichia coli strains used for cloning and overexpression (Table S1) were grown in Luria-Bertani (LB) medium at $37^{\circ} \mathrm{C}$ with the appropriate antibiotics; ampicillin $\left(100 \mu \mathrm{g} \mathrm{ml}^{-1}\right)$, erythromycin $\left(500 \mu \mathrm{g} \mathrm{ml}^{-1}\right)$ or chloramphenicol $\left(34 \mu \mathrm{g} \mathrm{ml}^{-1}\right)$.

Sulfolobus acidocaldarius (DSM639) (Table S1) was grown in Brock medium at $76^{\circ} \mathrm{C}$, with $\mathrm{pH}$ adjusted to 3.0 using sulphuric acid and supplemented with $0.1 \%(\mathrm{w} / \mathrm{v})$ tryptone (Brock et al., 1972).

\section{Construction of Neisseria gonorrhoeae strains}

An overview of plasmids created to construct $N$. gonorrhoeae strains is shown in Table S2. Primers used are described in Table S3. To generate a knockout of traB, flanking regions of traB were amplified by polymerase chain reaction (PCR) using the GGI-87F and GGI-88R, GGI-89F and GGI-90R primers on chromosomal DNA of $N$.gonorrhoeae strain MS11. These fragments were digested by Hindll and Kpnl and with $E c o R I$ and Sacl, respectively, and ligated into vector pSH001, resulting in vector pEP015_1. To construct pSH001, two PCR products amplified with primers ForwardDUS and ReverseDUS and primers ForwardErmC and ReverseErmC using pIDN1 as template were digested with EcoRI and Hindll and ligated. PCR product of tra $B$ fragment created with primers GGI-89F and GGI-90R was cloned in EcoRI and Sacl sites of pEP015_1, resulting in pEP015_2. Plasmid pEP015_2 was transformed to N. gonorrhoeae strain MS11 by natural transformation (Spence et al., 2008) resulting in strain MS11 $\Delta$ traB in which $t r a B$ is replaced by an ermC cassette. The replacement of traB by the ermC cassette was confirmed by PCR analysis and by sequencing of the PCR products. For the construction of the complementation strain MS11 $\operatorname{traB}:$ :traB, the deletion mutant MS11 $\Delta$ traB was transformed with genomic DNA of MS11. Transformants were selected for sensitivity to erythromycin. The presence of the insertion was determined by PCR and confirmed by sequencing of the region.

\section{Piliation state of $\mathrm{N}$. gonorrhoeae strains}

Piliation of different strains was first evaluated visually after growth on plates. The expression levels of PilE in the different $N$. gonorrhoeae strains were further assayed by Western blot analysis. Neisseria gonorrhoeae colonies were inoculated from over night grown plates in $3 \mathrm{ml}$ of prewarmed GCB medium, grown at $37^{\circ} \mathrm{C}$ with continuous shaking for $2 \mathrm{~h}$ and diluted in fresh medium to an $\mathrm{OD}_{600}$ of 0.2 . Growth was continued until an $\mathrm{OD}_{600}$ of 0.75 was reached and then cells were collected by centrifugation. The TriFast reagent (PEQLAB Biotechnologie GMBH, Erlangen, Germany) was used for total protein isolation. Protein isolation was performed according to the manufacturer's protocol. Isolated protein fractions were solubilized in $100 \mu \mathrm{l}$ SDS-Sample buffer, incubated at $75^{\circ} \mathrm{C}$ for $15 \mathrm{~min}$ and loaded on the SDSGel for further analysis. Western blotting was performed by transferring the protein from the gels on polyvinylidene difluoride membranes and incubating with 1:5000 dilution of PilE primary $A B$ and anti-mouse-AP conjugate secondary antibody (IBA). The chemiluminescence signal was obtained using the CDP-star substrate (Roche Diagnostics, Mannheim, Germany) on a LAS-4000 imager (GE Healthcare Europe, Freiburg, Germany).

\section{Construction of plasmids used for overexpression}

The construction of the plasmids used for overexpression in this study is described in Table S1.

\section{Expression and purification of TteSSB2, Sac7d, Exol and Exolll}

All proteins were overexpressed in Escherichia coli strain BL21pLysS. Cells were grown in 1 I of LB medium supplemented with $1 \%$ glucose at $37^{\circ} \mathrm{C}$ to an $\mathrm{OD}_{600}$ of 0.5 and induced with $0.5 \mathrm{mM}$ isopropyl $\beta$-D-1-thiogalactopyranoside. After $3 \mathrm{~h}$, the cells were harvested by centrifugation, resuspended in $30 \mathrm{ml}$ of buffer $\mathrm{A}\left(50 \mathrm{mM} \mathrm{NaPO}_{4}, 300 \mathrm{mM}\right.$ $\mathrm{NaCl}, \mathrm{pH} 8.0$ ) and stored at $-80^{\circ} \mathrm{C}$. Prior to purification, 
frozen cell pellets were thawed on ice. After thawing, the solution was supplemented with 1 tablet of protease inhibitor cocktail (Roche) and $1 \mathrm{mg}$ of DNase I (Roche), and the cells were disrupted by passing them three times through a highpressure cell disrupter (constant cell disruption systems) at 2300 bar. Cell debris was removed by centrifugation at 10000 r.p.m. in an F10S-6x500y rotor (Thermo Fischer Scientific, Waltham, MA, USA), and the supernatant was filtered through a $0.45 \mu \mathrm{m}$ filter. Purifications were performed on an ÄKTA-Purifier system (GE Healthcare, Little Chalfont, Buckinghamshire, UK).

His-tagged Exol, Exolll and Sac7d were purified by loading the clarified supernatant on a $1 \mathrm{ml} \mathrm{Hi}$-Trap Chelating column (GE Healthcare) preloaded with $0.1 \mathrm{M} \mathrm{NiSO}_{4}$ and equilibrated in buffer $A$. The column was washed with 10 column volumes of buffer $A$ and bound proteins were eluted with a linear gradient of buffer A supplemented with $400 \mathrm{mM}$ imidazole. Peak fractions containing proteins were pooled and diluted with two volumes of buffer $\mathrm{B}(10 \mathrm{mM}$ Tris- $\mathrm{HCl} \mathrm{pH} 8.0,10 \mathrm{mM}$ $\mathrm{NaCl}$ ). This sample was loaded on a Hi-Trap Q column (GE Healthcare) equilibrated with buffer $B$, and the protein was eluted with a linear gradient up to $1 \mathrm{M} \mathrm{NaCl}$ in buffer $\mathrm{B}$. Fractions containing proteins were concentrated to $2 \mathrm{ml}$ using Amicon Ultra - 10K Concentrators (Millipore, Billerica, MA, USA). Finally, these fractions were loaded on a Superdex SD200 gelfiltration column (GE Healthcare), equilibrated with buffer $\mathrm{C}$ containing $150 \mathrm{mM} \mathrm{NaCl}$ and $20 \mathrm{mM}$ Tris- $\mathrm{HCl} \mathrm{pH}$ 8.0. Fractions containing proteins were pooled and frozen in liquid $\mathrm{N}_{2}$ until further use.

To purify TteSSB2, the disrupted cell suspension was heated for $15 \mathrm{~min}$ at $75^{\circ} \mathrm{C}$, followed by centrifugation at 10000 r.p.m. in an F10S-6x500y rotor (FiberLite). The supernatant was filtered through a $0.45 \mu \mathrm{m}$ filter. The filtrate was loaded on Hi-Trap Q column (GE Healthcare) equilibrated with buffer $\mathrm{B}$, and the protein was eluted with a linear gradient up to $1 \mathrm{M} \mathrm{NaCl}$ in buffer $\mathrm{B}$. Fractions containing proteins were concentrated to $2 \mathrm{ml}$ using Amicon Ultra - 10K concentrators (Millipore). Finally, these fractions were loaded on a Superdex SD200 gelfiltration column (GE Healthcare), equilibrated with buffer $\mathrm{C}$ containing $150 \mathrm{mM} \mathrm{NaCl}$ and $20 \mathrm{mM}$ Tris- $\mathrm{HCl} \mathrm{pH}$ 8.0. Fractions containing proteins were pooled, and frozen in liquid $\mathrm{N}_{2}$ until further usage.

\section{Site-specific labelling of proteins via cysteines}

Prior to labelling of the cysteines, purified proteins were reduced by incubation with $10 \mathrm{mM}$ tris[2-carboxyethyl] phosphine for $10 \mathrm{~min}$ on ice. Two microlitres of $50 \mathrm{mM}$ stock solution of the fluorescent probe was added to a total volume of $200 \mu \mathrm{l}$ containing the protein of interest at a concentration of $100 \mu \mathrm{M} \mathrm{ml}^{-1}$ in buffer C. Labelling was performed in the dark for $2 \mathrm{~h}$ at room temperature. The reaction was stopped by addition of $10 \mathrm{mM}$ glutathione. Access of dye and glutathione was removed by separation of the reaction solution on a $2 \mathrm{ml} \mathrm{PD-column} \mathrm{(GE} \mathrm{Healthcare)} \mathrm{equilibrated} \mathrm{with}$ buffer $\mathrm{C}$. Fractions containing the labelled protein were frozen in liquid $\mathrm{N}_{2}$ until further use.

\section{Fluorescence titrations}

Titrations of $50 \mathrm{nM}$ fluorescently labelled protein were performed with increasing concentrations [0-200 nM] of
M13 ssDNA (TteSSB2) or M13 dsDNA (Sac7d). Experiments were performed on a temperature-controlled PC1 spectrofluorometer (ISS, Champaign, IL, USA) with a cooled photomultiplier. The excitation wavelength was set to $472 \mathrm{~nm}$ and the emission wavelength to $536 \mathrm{~nm}$ for IANBD. The slit widths for the excitation and the emission beam were set to 1 and $2 \mathrm{~nm}$ respectively. Experiments were performed in a $60 \mu \mathrm{l}$ cuvette at $8^{\circ} \mathrm{C}$ in a buffer containing $20 \mathrm{mM}$ Tris $\mathrm{pH} 7.5$ and $1 \mathrm{mM}$ dithiothreitol, and samples were allowed to equilibrate for $90 \mathrm{~s}$ between measurements.

\section{Electrophoretic mobility shift assays}

To determine the binding efficiency of purified TteSSB2 and Sac7d to ssDNA and dsDNA, a dT ${ }_{90}$ oligonucleotide labelled with Cy3 at the 5' end and a 468 bp PCR product obtained with an unlabelled primer (407R-GGI) and a Cy3-labelled primer (790R-GGI) were used. $20 \mathrm{nM}$ of labelled $\mathrm{dT}_{90}$ oligonucleotide or the PCR product was mixed with increasing concentrations $(0-5000 \mathrm{nM})$ of TteSSB2 or Sac7d in SBA buffer (10 mM NaOH, $2 \mathrm{mM}$ EDTA, titrated to $\mathrm{pH} 7.5$ with boric acid) in a total volume of $12 \mu \mathrm{l}$. The reaction solutions were incubated at $4^{\circ} \mathrm{C}$ for 15 min after which the reaction was mixed with $3 \mu \mathrm{l} 40 \%$ sucrose. The aliquots were analysed by electrophoresis on $7.5 \%$ native polyacrylamide gels in SBA buffer. The fluorescently labelled DNA was visualized on a LAS-4000 imager (Fujifilm).

\section{Activity assays for specificity of Exol}

The specificity of Exol for ssDNA and dsDNA was tested using a $\mathrm{dT}_{90}$ oligonucleotide labelled with Сy3 at the 5' end, and a $468 \mathrm{bp}$ PCR product obtained with an unlabelled primer (407R-GGI) and a Cy3-labelled primer (790R-GGI). The reactions were performed in the growth medium used in the continuous flow experiments (Graver-Wade medium diluted 1:5 with phosphate buffered saline). Shortly, $150 \mathrm{ng}$ of the $\mathrm{dT}_{90}$ oligonucleotide or the PCR product was mixed with increasing concentrations of Exol $(0-5000 \mathrm{nM})$ in a total volume of $12 \mu \mathrm{l}$. The reaction was incubated at $37^{\circ} \mathrm{C}$ for $1 \mathrm{~h}$ after which the reaction was mixed with $3 \mu \mathrm{l} 40 \%$ sucrose and $10 \%$ SDS. The aliquots were analysed by electrophoresis on $7.5 \%$ native polyacrylamide gels using an SBA buffer system. The fluorescently labelled DNA was visualized on a LAS4000 imager (Fujifilm).

\section{Fluorescent light microscopy}

To perform light microscopy, $N$. gonorrhoeae colonies were scraped from overnight grown plates and diluted in GraverWade medium (Wade and Graver, 2007) supplemented with Kellogg's supplements and $0.042 \% \mathrm{NaHCO}_{3}$. Cultures were grown at $37^{\circ} \mathrm{C}$ constantly shaken at 140 r.p.m. Cells were grown to an $\mathrm{OD}_{600}$ of 0.8 , collected by centrifugation and diluted in fresh medium. This procedure was repeated at least three times, until most DNA derived from lysed cells was removed. Samples were collected directly after the last dilution. When the indicated enzymes ( $1 \mu \mathrm{M}$ Exol) or M13 ssDNA (final concentration $0.0625 \mu \mathrm{gr} \mathrm{ml}^{-1}$ ) were added, incubation was continued for $15 \mathrm{~min}$. Two microlitres of the cell suspen- 
sion was loaded on the glass slide covered with $1 \%$ agarose. Microscopy and image acquisition was performed on a Zeiss Imager M1 (Zeiss, Göttingen, Germany). Image data obtained were processed with Metamorph software (Molecular Devices, Sunnyvale, CA, USA).

\section{Confocal laser microscopy}

For continuous-flow chamber experiments with N.gonorrhoeae, a Graver-Wade medium supplemented with Kellogg's supplements and $0.042 \% \mathrm{NaHCO}_{3}$ diluted $1: 5$ with PBS was used. Colonies from three plates grown overnight were collected and inoculated in $3 \mathrm{ml}$ prewarmed GraverWade medium. Cultures were grown to an $\mathrm{OD}_{600}$ of 0.8 ; diluted 1:1000 with fresh Graver-Wade medium and $200 \mu \mathrm{l}$ of the diluted cell suspension was inoculated in the continuousflow chamber. Flow chamber experiments were performed as described previously (Lappann et al., 2006). Strains were grown in three separate channels. From each channel, at least six image stacks were acquired. For a continuous incubation with Exol, Exol was added to a final concentration of $1 \mu \mathrm{M}$ to the medium used to perfuse the continuous-flow chamber. The perfusion medium was exchanged every $2 \mathrm{~h}$ with medium with freshly thawed Exol. When the effect of Exol on $24 \mathrm{~h}$ old biofilms was studied, Exol was injected directly into the channels. The flow rate was stopped for $1 \mathrm{~h}$, and continued after the incubation. To exclude the effect of stopped flow, one channel was inoculated with medium not containing enzymes and compared afterwards with the channels containing enzymes. Microscopy and image acquisition was performed on a Leica TCS SP5 (Leica Microsystems, Wetzlar, Germany). Images were processed, and for the quantification of the biofilm mass, the total number of voxels was calculated with IMARIS software (Bitplane, Zurich, Switzerland). Voxel numbers from five distinct channels were determined. An average number and an error bar from five calculations are used for the final picture. At least two fully independent experiments were performed. Biofilm experiments with different Sulfolobus spp. were performed as described previously (Koerdt et al., 2010).

\section{Visualization of ssDNA/dsDNA in the biofilms}

For visualization of DNA in the biofilms, either $500 \mathrm{nM}$ labelled TteSSB2 or $500 \mathrm{nM}$ labelled Sac7d was inoculated into the channels. After $10 \mathrm{~min}$, the flow was resumed to wash away unbound protein.

\section{Acknowledgements}

This work was supported by a travel grant from the Boeringer Ingelheim Foundation. We thank Emilia Pachulec for creating the MS11 $\Delta$ traB strain, Shakib Hakimi for constructing plasmid pSH001, Julia Godeke for her help with the CLSM microscope and Jürgen Koch for technical assistance with the protein purifications. AK and SVA were supported by intramural funds of the Max Planck Society.

\section{References}

Allesen-Holm, M., Barken, K.B., Yang, L., Klausen, M., Webb, J.S., Kjelleberg, S., et al. (2006) A characterization of DNA release in Pseudomonas aeruginosa cultures and biofilms. Mol Microbiol 59: 1114-1128.

Bockelmann, U., Janke, A., Kuhn, R., Neu, T.R., Wecke, J., Lawrence, J.R., and Szewzyk, U. (2006) Bacterial extracellular DNA forming a defined network-like structure. FEMS Microbiol Lett 262: 31-38.

Brock, T.D., Brock, K.M., Belly, R.T., and Weiss, R.L. (1972) Sulfolobus: a new genus of sulfur-oxidizing bacteria living at low $\mathrm{pH}$ and high temperature. Arch Mikrobiol 84: 5468.

Chan, Y.A., Hackett, K.T., and Dillard, J.P. (2012) The lytic transglycosylases of Neisseria gonorrhoeae. Microb Drug Resist 18: 271-279.

Costerton, J.W., Stewart, P.S., and Greenberg, E.P. (1999) Bacterial biofilms: a common cause of persistent infections. Science 284: 1318-1322.

Das, T., Sharma, P.K., Busscher, H.J., van der Mei, H.C., and Krom, B.P. (2010) Role of extracellular DNA in initial bacterial adhesion and surface aggregation. Appl Environ Microbiol 76: 3405-3408.

Davies, D. (2003) Understanding biofilm resistance to antibacterial agents. Nat Rev Drug Discov 2: 114-122.

Dillard, J.P., and Seifert, H.S. (2001) A variable genetic island specific for Neisseria gonorrhoeae is involved in providing DNA for natural transformation and is found more often in disseminated infection isolates. Mol Microbiol 41: 263277.

Dorward, D.W., Garon, C.F., and Judd, R.C. (1989) Export and intercellular transfer of DNA via membrane blebs of Neisseria gonorrhoeae. J Bacteriol 171: 2499-2505.

Dunne, W.M., Jr (2002) Bacterial adhesion: seen any good biofilms lately? Clin Microbiol Rev 15: 155-166.

Edwards, J.L., and Apicella, M.A. (2004) The molecular mechanisms used by Neisseria gonorrhoeae to initiate infection differ between men and women. Clin Microbiol Rev 17: 965-981. Table of contents.

Elmros, T., Burman, L.G., and Bloom, G.D. (1976) Autolysis of Neisseria gonorrhoeae. J Bacteriol 126: 969-976.

Ferretti, J.J., Dyer, D.W., and Roe, B.A. (1997) Data available. Nature 386: 320.

Flemming, H.C., and Wingender, J. (2010) The biofilm matrix. Nat Rev Microbiol 8: 623-633.

Fuxman Bass, J.I., Russo, D.M., Gabelloni, M.L., Geffner, J.R., Giordano, M., Catalano, M., et al. (2010) Extracellular DNA: a major proinflammatory component of Pseudomonas aeruginosa biofilms. $J$ Immunol 184: 63866395.

Gao, Y.G., Su, S.Y., Robinson, H., Padmanabhan, S., Lim, L., McCrary, B.S., et al. (1998) The crystal structure of the hyperthermophile chromosomal protein Sso7d bound to DNA. Nat Struct Biol 5: 782-786.

Godeke, J., Paul, K., Lassak, J., and Thormann, K.M. (2011a) Phage-induced lysis enhances biofilm formation in Shewanella oneidensis MR-1. ISME J 5: 613-626.

Godeke, J., Heun, M., Bubendorfer, S., Paul, K., and Thormann, K.M. (2011b) Roles of two Shewanella oneidensis MR-1 extracellular endonucleases. Appl Environ Microbiol 77: 5342-5351.

Greiner, L.L., Edwards, J.L., Shao, J., Rabinak, C., Entz, D., and Apicella, M.A. (2005) Biofilm formation by Neisseria gonorrhoeae. Infect Immun 73: 1964-1970. 
Hamilton, H.L., Schwartz, K.J., and Dillard, J.P. (2001) Insertion-duplication mutagenesis of neisseria: use in characterization of DNA transfer genes in the gonococcal genetic island. J Bacteriol 183: 4718-4726.

Hamilton, H.L., Dominguez, N.M., Schwartz, K.J., Hackett, K.T., and Dillard, J.P. (2005) Neisseria gonorrhoeae secretes chromosomal DNA via a novel type IV secretion system. Mol Microbiol 55: 1704-1721.

Hara, T.U., and Ueda, S. (1981) A study on the mechanism of DNA excretion from P. aeruginosa Kyu-1 - effect of mitomycin-C on extracellular DNA production. Agric Biol Chem 45: 2457-2461.

Harmsen, M., Lappann, M., Knochel, S., and Molin, S. (2010) Role of extracellular DNA during biofilm formation by Listeria monocytogenes. Appl Environ Microbiol 76: 22712279.

Izano, E.A., Shah, S.M., and Kaplan, J.B. (2009) Intercellular adhesion and biocide resistance in nontypeable Haemophilus influenzae biofilms. Microb Pathog 46: 207213.

Jurcisek, J.A., and Bakaletz, L.O. (2007) Biofilms formed by nontypeable Haemophilus influenzae in vivo contain both double-stranded DNA and type IV pilin protein. $J$ Bacteriol 189: 3868-3875.

Kadurugamuwa, J.L., and Beveridge, T.J. (1996) Bacteriolytic effect of membrane vesicles from Pseudomonas aeruginosa on other bacteria including pathogens: conceptually new antibiotics. J Bacteriol 178: 2767-2774.

Kellogg, D.S. Jr, Peacock, W.L. Jr, Deacon, W.E., Brown, L., and Pirkle, D.I. (1963) Neisseria gonorrhoeae. I. Virulence genetically linked to clonal variation. J Bacteriol 85: 12741279.

Koerdt, A., Godeke, J., Berger, J., Thormann, K.M., and Albers, S.V. (2010) Crenarchaeal biofilm formation under extreme conditions. PLOS ONE 5: e14104.

Lappann, M., Haagensen, J.A., Claus, H., Vogel, U., and Molin, S. (2006) Meningococcal biofilm formation: structure, development and phenotypes in a standardized continuous flow system. Mol Microbiol 62: 1292-1309.

Lappann, M., Claus, H., van Alen, T., Harmsen, M., Elias, J., Molin, S., and Vogel, U. (2010) A dual role of extracellular DNA during biofilm formation of Neisseria meningitidis. Mol Microbiol 75: 1355-1371.

Lemming, H.C., Wingender, J., Griegbe, T., and Mayer, C. (2000) Physicochemical Properties of Biofilms in Biofilms: Recent Advances in their Study and Control. Amsterdam, The Netherlands: Harwood Academic Publishers.

Lohman, T.M., and Ferrari, M.E. (1994) Escherichia coli single-stranded DNA-binding protein: multiple DNAbinding modes and cooperativities. Annu Rev Biochem 63: 527-570.

Mann, E.E., Rice, K.C., Boles, B.R., Endres, J.L., Ranjit, D., Chandramohan, L., et al. (2009) Modulation of eDNA release and degradation affects Staphylococcus aureus biofilm maturation. PLOS ONE 4: e5822.

Moscoso, M., Garcia, E., and Lopez, R. (2006) Biofilm formation by Streptococcus pneumoniae: role of choline, extracellular DNA, and capsular polysaccharide in microbial accretion. J Bacteriol 188: 7785-7795.

Mulcahy, H., Charron-Mazenod, L., and Lewenza, S. (2008) Extracellular DNA chelates cations and induces antibiotic resistance in Pseudomonas aeruginosa biofilms. PLOS Pathog 4: e1000213.

O'Toole, G.A., and Kolter, R. (1998) Flagellar and twitching motility are necessary for Pseudomonas aeruginosa biofilm development. Mol Microbiol 30: 295-304.

Pariser, H. (1972) Asymptomatic gonorrhea. Med Clin North Am 56: 1127-1132.

Qin, Z., Ou, Y., Yang, L., Zhu, Y., Tolker-Nielsen, T., Molin, S., and Qu, D. (2007) Role of autolysin-mediated DNA release in biofilm formation of Staphylococcus epidermidis. Microbiology 153: 2083-2092.

Ramsey, M.E., Woodhams, K.L., and Dillard, J.P. (2011) The gonococcal genetic island and type IV secretion in the Pathogenic neisseria. Front Microbiol 2: 61, 1-9.

Rice, K.C., Mann, E.E., Endres, J.L., Weiss, E.C., Cassat, J.E., Smeltzer, M.S., and Bayles, K.W. (2007) The cidA murein hydrolase regulator contributes to DNA release and biofilm development in Staphylococcus aureus. Proc Natl Acad Sci USA 104: 8113-8118.

Salgado-Pabon, W., Jain, S., Turner, N., van der Does, C., and Dillard, J.P. (2007) A novel relaxase homologue is involved in chromosomal DNA processing for type IV secretion in Neisseria gonorrhoeae. Mol Microbio/66: 930947.

Seifert, H.S. (1992) Molecular mechanisms of antigenic variation in Neisseria gonorrhoeae. Mol Cell Biol Hum Dis Ser 1: 1-22.

Seifert, H.S., Ajioka, R., and So, M. (1988) Alternative model for Neisseria gonorrhoeae pilin variation. Vaccine 6: 107109.

Spence, J.M., Wright, L., and Clark, V.L. (2008) Laboratory maintenance of Neisseria gonorrhoeae. Curr Protoc Microbiol. 8: 4A.1.1-4A.1.26.

Steichen, C.T., Shao, J.Q., Ketterer, M.R., and Apicella, M.A. (2008) Gonococcal cervicitis: a role for biofilm in pathogenesis. J Infect Dis 198: 1856-1861.

Steichen, C.T., Cho, C., Shao, J.Q., and Apicella, M.A. (2011) The Neisseria gonorrhoeae biofilm matrix contains DNA, and an endogenous nuclease controls its incorporation. Infect Immun 79: 1504-1511.

Steinberger, R.E., and Holden, P.A. (2005) Extracellular DNA in single- and multiple-species unsaturated biofilms. Appl Environ Microbiol 71: 5404-5410.

Thomas, V.C., Thurlow, L.R., Boyle, D., and Hancock, L.E. (2008) Regulation of autolysis-dependent extracellular DNA release by Enterococcus faecalis extracellular proteases influences biofilm development. J Bacteriol 190: 5690-5698.

Thomas, V.C., Hiromasa, Y., Harms, N., Thurlow, L., Tomich, J., and Hancock, L.E. (2009) A fratricidal mechanism is responsible for eDNA release and contributes to biofilm development of Enterococcus faecalis. Mol Microbiol 72: 1022-1036.

Wade, J.J., and Graver, M.A. (2007) A fully defined, clear and protein-free liquid medium permitting dense growth of Neisseria gonorrhoeae from very low inocula. FEMS Microbiol Lett 273: 35-37.

Webb, J.S., Thompson, L.S., James, S., Charlton, T., Tolker-Nielsen, T., Koch, B., et al. (2003) Cell death in Pseudomonas aeruginosa biofilm development. J Bacteriol 185: 4585-4592. 
Whitchurch, C.B., Tolker-Nielsen, T., Ragas, P.C., and Mattick, J.S. (2002) Extracellular DNA required for bacterial biofilm formation. Science 295: 1487.

Yang, S.J., Dunman, P.M., Projan, S.J., and Bayles, K.W. (2006) Characterization of the Staphylococcus aureus CidR regulon: elucidation of a novel role for acetoin metabolism in cell death and lysis. Mol Microbiol 60: 458-468.

Zhang, S., Yang, H., Li, L., Tian, Y., and Tan, H. (2009) Novel ssDNA-binding properties of SSB2 and SSB3 from Thermoanaerobacter tengcongensis. Wei Sheng Wu Xue Bao 49: 453-459.

\section{Supporting information}

Additional Supporting Information may be found in the online version of this article at the publisher's web-site:

Fig. S1. Purification and characterization of Exonuclease I. His-tagged Exonuclease I was purified by Ni-NTA affinity, anion exchange and gel filtration chromatography. (A) Histagged Exonuclease I was essentially pure as assayed by Coomassie staining of an SDS-PAGE of the purified protein. (B) Exonuclease I eluted as a monomer from the SD200 gel filtration column column. The positions of the various markers for both the gel filtration and the SDS-PAGE are indicated. To test the specificity of the purified Exonuclease I, $150 \mathrm{ng}$ of a Cy3-labelled dT90 oligonucleotide (C) or $150 \mathrm{ng}$ of a Cy3labelled PCR product (D) were incubated with an increasing concentrations of Exonuclease I for $1 \mathrm{~h}$ at $37^{\circ} \mathrm{C}$. The fluorescently labelled DNA was analysed after separation on a $7.5 \%$ polyacrylamide gels sing a LAS-4000 imager.

Fig. S2. Purification and specificity of the ssDNA binding protein TteSSB2. TteSSB2 was overproduced in E. coli and purified by a heat-step followed by anion exchange and gel filtration chromatography. (A) Coomassie staining of an SDS-PAGE of the purified protein. (B) TteSSB2 eluted as a tetramer from the SD200 gel filtration column and was essentially pure. The positions of the various markers for both the gel filtration and the SDS-PAGE are indicated. Electromobility shift assays were performed with incubating either a Cy3-labelled dT90 oligonucleotide (C) or a Cy3labelled PCR product (D) with increasing concentration of TteSSB2. The fluorescently labelled DNA was analysed after separation on $7.5 \%$ polyacrylamide gels using a LAS4000 imager.

Fig. S3. Purification and specificity of the DNA binding protein Sac7d. His-tagged Sac7d was overproduced in E. coli and purified by Ni-NTA affinity, anion exchange and gel filtration chromatography. (A) Coomassie staining of an SDSPAGE of the purified protein. (B) Sac7d eluted as a monomer from the SD200 gel filtration column. The positions of the various markers for both the gel filtration and the SDS-PAGE are indicated. Electromobility shift assays were performed with incubating either a Cy3-labelled dT90 oligonucleotide (C) or a Cy3-labelled PCR product (D) with increasing concentration of Sac7d. The fluorescently labelled DNA was analysed after separation on $7.5 \%$ polyacrylamide gels using a LAS-4000 imager.

Table S1. Strains used in this study.

Table S2. Plasmids used in this study.

Table S3. Primers used in this study.

Table S4. Increase in fluorescence upon binding to DNA for TteSSB2 and Sac7d labelled at different positions.

Supplementary Material and Methods: includes supplementary methods, figures and tables.

Supplementary References: contains references cited in supplementary material and methods. 